\title{
HYBRID FILTERS TO DAMP HARMONIC RESONANCE IN POWER TRANSMISSION SYSTEMS
}

\author{
Lucas F. Encarnação ${ }^{1}$, Alexandre G. Merçon ${ }^{2}$, Hélio H. de Almeida ${ }^{3}$ \\ Emanuel L. van Emmerik ${ }^{4}$, Maurício Aredes ${ }^{5}$ \\ ${ }_{1,2,4,5}$ Power Electronics Laboratory, Electrical Engineering Program, COPPE/Federal University of Rio de Janeiro, Brazil \\ ${ }^{4}$ Dept. of Electrical Engineering, Technical University Delft, The Netherlands \\ ${ }^{3}$ Furnas Centrais Elétricas S.A., Brazil \\ (lucas ${ }^{1}$, alexandre ${ }^{2}$, emmerik $^{4}$, aredes $\left.{ }^{5}\right) @$ coe.ufrj.br, (hhayashi $\left.{ }^{3}\right) @$ furnas.com.br
}

\begin{abstract}
Problems related to harmonic propagation in transmission systems have been noticed in the last years. Passive filters, commonly used to attenuate noncharacteristic harmonics in HVDC systems, stay at risk of disconnection from the system due to overcurrents. One of the possible solutions to solve the problem of high harmonic levels would be the use of pure active filters. However, this alternative may be very expensive due to the high power of the transmission systems. This paper relates to a comparative study on two different topologies of hybrid filters to damp harmonic resonance in power transmission systems. The first one combines a smallrated active filter in series with passive filters, limiting overcurrents, when existent, or improving the quality factor of the filter when the passive filters work under its nominal current. The second one consists of an active filter in parallel with passive filters, compensating all eventual overcurrent in these. Simulation results with the two proposed topologies present the efficiency of, and the differences between, the hybrid filters in power transmission systems.
\end{abstract}

Keywords - Harmonic resonance, power transmission systems, hybrid filters, HVDC, power converters, power quality.

\section{INTRODUCTION}

The harmonic propagation in industrial power systems has become a problem that affects seriously the power quality in distribution feeders due to the wide use of non-linear loads such as rectifiers, inverters and cycloconverters [1]. This problem is even more amplified because of the use of shunt capacitors installed on distribution systems for power factor correction. Normally, these capacitive filters are designed considering only the fundamental frequency of the system, 50 or $60 \mathrm{~Hz}$. The harmonic propagation generated by power electronic equipments may cause harmonic resonance between the line inductances and those shunt capacitors. Researches on harmonic damping in distribution systems are in advanced stage and the use of active filters have presented good results [2]-[3].

Recently, problems related to harmonic propagation have also been noticed in transmission systems, affecting the electric system in a severe way. Important parts of the Brazilian transmission system, like the area connected to the

Manuscript received on May 31, 2005; first revision on July 27, 2005; second revision on October 5, 2005.

Recommended by the Editor José Antenor Pomilio.
High Voltage Direct Current (HVDC) system, have been presenting this kind of problems [4].

Passive filters at the Ibiúna substation, one of the converter stations of the Brazilian HVDC system, were designed to attenuate the harmonics generated by the converters as well as the non-characteristic harmonics generated by asymmetries in the converter transformers and the firing control. Since 1988, situations with high indices of harmonic distortion, mainly the $5^{\text {th }}$ order harmonic, have been detected. Due to these high indices it was necessary to operate with two double-tuned passive filters for the $3^{\text {rd }}$ and $5^{\text {th }}$ harmonics. This is in disagreement with the original project, which was designed to operate with only one filter at this tuning, letting the other one as a backup filter.

At the Ibiúna substation, a pure active filter to solve the problem of the high $5^{\text {th }}$ order harmonic voltage in the passive filters would not be economically and technically viable because of the high power of the system. A hybrid filter, consisting of an active filter combined with the existent passive filters, would be a less expensive solution, uniting the advantages of both filters [5]-[6].

This paper, which is a result of an R\&D program between Furnas Centrais Elétricas S.A. and the Laboratory of Power Electronics at COPPE/UFRJ, proposes two hybrid filter topologies to work in high power systems such as HVDC systems. The first topology consists of an active filter in series with passive filters and the second one consists of an active filter in parallel with the passive filters. In both topologies the hybrid filter is in shunt with the system.

\section{THE IBIÚNA SUBSTATION}

The Ibiúna substation is a part of the South - Southeast Central West Brazilian transmission system, as shown in Figure 1.

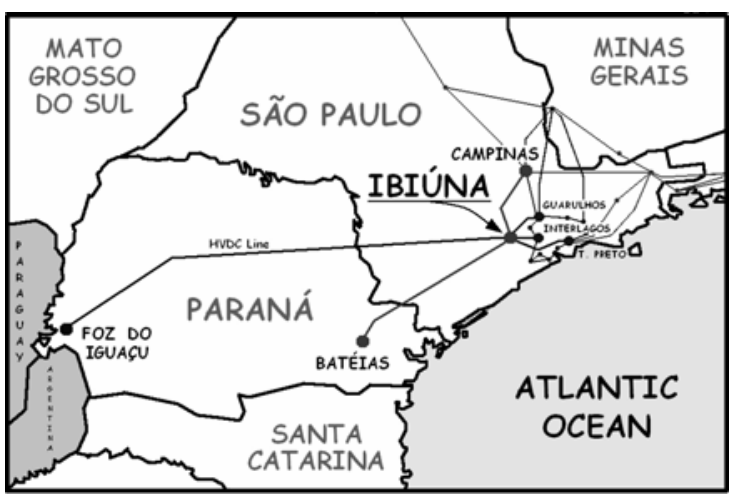

Fig. 1. Ibiúna and its connections with the South-Southeast-Central West Brazilian transmission system. 
Ibiúna is an illustrative example of a complex system containing a wide variety of power-system equipments such as HVDC converters, passive filter banks, synchronous compensators and transmission lines with different AC levels coming from various parts of the power system.

With the purpose of testing the proposed hybrid filters, the transmission system was modeled and simulated at PSCAD/EMTDC ${ }^{\mathrm{TM}}$ version 3.0.8. In the developed model all transmission lines are based on tower geometry (frequency dependent phase model), and those that are transposed were in accordance with the actual situation; the loads modeled in different parts of the system are in accordance with the light load scenario of august 2003, provided by ONS (Brazilian National Operator ). The complexity of this system has lead to a digital model with more than 2200 electrical nodes, besides the HVDC and machine control circuits.

Figure 2 presents a simplified schematic of Ibiúna's $345 \mathrm{kV}$ bus where the active filters will be installed together with the existent passive filters. Three double circuit transmission lines are connected to this bus: Ibiúna Interlagos, Ibiúna - Tijuco Preto and Ibiúna-Guarulhos. Moreover, the following equipments are connected to the Ibiúna bus bar: synchronous compensators, HVDC converters, transformers and the banks of passive filters where the high indices of the $5^{\text {th }}$ harmonic were detected.

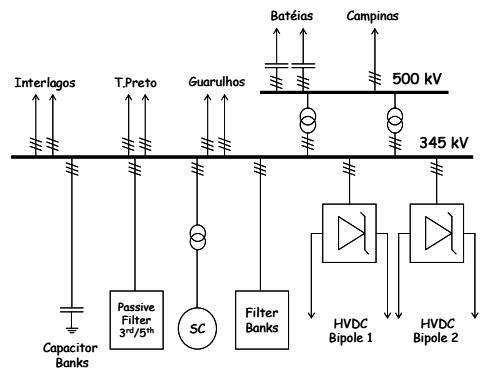

Fig. 2. Simplified schematic of the Ibuina's $345 \mathrm{kV}$ bus.

\section{SERIES HYBRID FILTER}

\section{A. Power Circuit}

In the first topology, the hybrid filter is composed of an active filter in series with the existent passive filters. The power circuit of the active filter consists of three singlephase voltage-source Pulse Width Modulation (PWM) inverters, with a switching frequency of $5 \mathrm{kHz}$, using four IGBTs and one capacitor per phase. The inverter uses the $5^{\text {th }}$ harmonic tuned passive filters as output filters to eliminate the high frequency harmonic components.

Figure 3 shows the three-phase equivalent circuit of the hybrid filter connected to the Ibiúna's $345 \mathrm{kV}$ bus. As illustrated, the active filter is located under the passive filters, therefore, working at a small voltage rate. Due to adequate voltage and current levels this configuration allows the use of small rated devices in the active filter and it was not necessary to connect a matching transformer between the active and the passive filters. The instantaneous voltage drops over the IGBTs are defined by the capacitor voltages, which were maintained below $3.15 \mathrm{kV}$ during the simulations. This way, the power circuit could work with standard IGBT modules without the necessity to connect more modules in series [7].

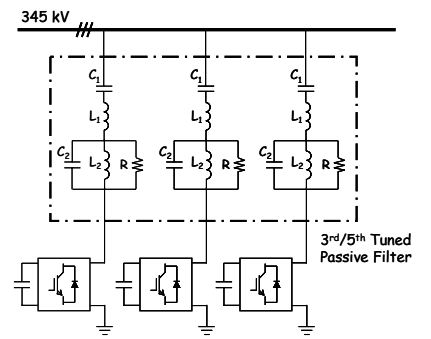

Fig. 3. Series hybrid filter installed at the $345 \mathrm{kV}$ bus.

The passive filters impedance variation in the frequency domain is shown in Figure 4. As it can be seen, even at the tuned frequencies, $5^{\text {th }}$ harmonic for example, the passive filters present non-zero impedance, which causes a poor quality factor. For the switching frequency $(5 \mathrm{kHz})$ the passive filters present a high impedance (higher then $10 \mathrm{k} \Omega$ ), which blocks the $5^{\text {th }}$ harmonic current of achieving the $345 \mathrm{kV}$ bus. Equation (1), with variables presented in Figure 3, describes the impedance of the passive filters in the frequency domain.

$$
Z(j \omega)=j \omega L_{1}+\frac{1}{j \omega C_{1}}+\left(\frac{R-\omega^{2} L_{2} C_{2} R+j \omega L_{2}}{j \omega L_{2} R}\right)
$$

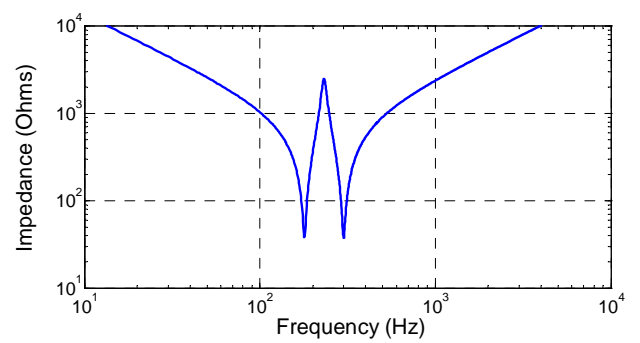

Fig. 4. Passive filters impedance module in the frequency domain.

\section{B. Operation Principles}

The active filter works in two distinct situations. When the nominal current in the passive filters is not achieved, the active filter behaves like a negative resistance, generating a proportional voltage in counter-phase with the detected $5^{\text {th }}$ harmonic current. This cancels the resistance of the passive filters and improves its quality factor. When an overcurrent occurs, the active filter increases the resistance of the passive filters, generating a proportional voltage in phase with the detected $5^{\text {th }}$ harmonic current, protecting it from an excessive current value. This control principle is shown in Figure 5.

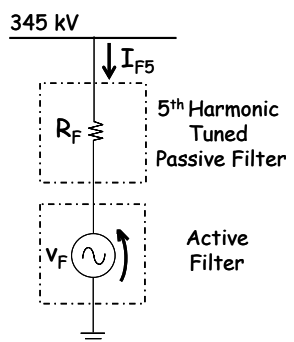

Fig. 5. Single-phase equivalent circuit for the series hybrid filter. 


\section{Detection Circuit}

Two detection circuits are used to separate the $1^{\text {st }}$ and the $5^{\text {th }}$ current harmonics in the passive filters. The detected phase of the fundamental current is used to control the capacitor voltage in each of the single-phase power circuits. The detected $5^{\text {th }}$ harmonic current is used to control the current level in the passive filters, compensating the extra current or improving the quality factor of the passive filters. The detection circuits are shown in Figure 6.

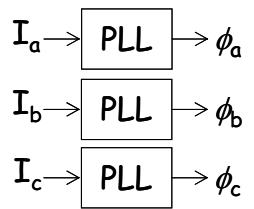

(a)

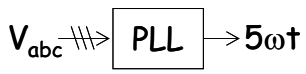

(b)

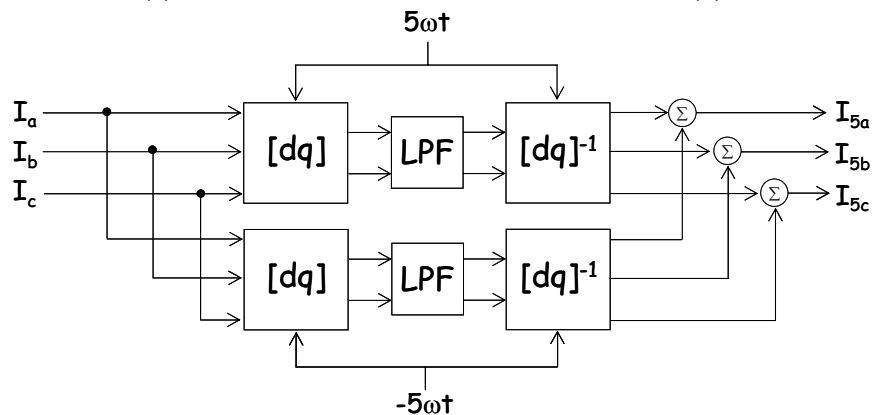

(c)

Fig. 6. $1^{\text {st }}$ harmonic phase detection circuit (a), PLL circuit used in the $5^{\text {th }}$ harmonic frequency detection (b) and $5^{\text {th }}$ harmonic detection circuit (c).

Three Phase-Locked Loops (PLLs) [8]-[9], are used to detect each phase of the fundamental current in the passive filters $\left(\phi_{\mathrm{a}}, \phi_{\mathrm{b}}, \phi_{\mathrm{c}}\right)$, as in Figure 6.a. This information is used in the control circuit to charge and discharge the capacitors.

A three-phase PLL, Figure 6.b, detects the fundamental frequency in the passive filters, generating the phase reference used in the $\mathrm{d}-\mathrm{q}$ transformation, as in Figure 6.c. The three-phase currents are transformed to $d-q$ coordinates with its axes rotating five times the fundamental frequency $(5 \omega \mathrm{t})$. This manner, only the $5^{\text {th }}$ harmonic positive sequence current is converted in two DC components and all the other harmonics, including the fundamental, in $\mathrm{AC}$ components. The $5^{\text {th }}$ harmonic positive sequence current is extracted by a low pass filter with a corner frequency of $0.1 \mathrm{~Hz}$. The phase and the magnitude of the $5^{\text {th }}$ harmonic positive-sequence current are detected when the inverse $\mathrm{d}-\mathrm{q}$ transform is applied, that generates $5^{\text {th }}$ harmonic three-phase positivesequence currents. The same procedure is used, with its axes rotating five times the fundamental frequency in the opposite direction $(-5 \omega \mathrm{t})$, to generate $5^{\text {th }}$ harmonic three-phase negative-sequence currents. The positive and negative $5^{\text {th }}$ harmonic currents are added, in each phase, to generate the three-phase $5^{\text {th }}$ harmonic currents.

\section{Control Circuit}

The control circuit consists of two distinct parts. The first one controls the capacitor voltages in the power circuit, Figure 7.a, and the second one regulates the $5^{\text {th }}$ harmonic current in the passive filters, Figure 7.b.

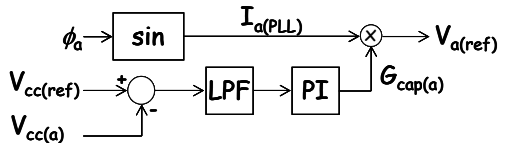

(a)

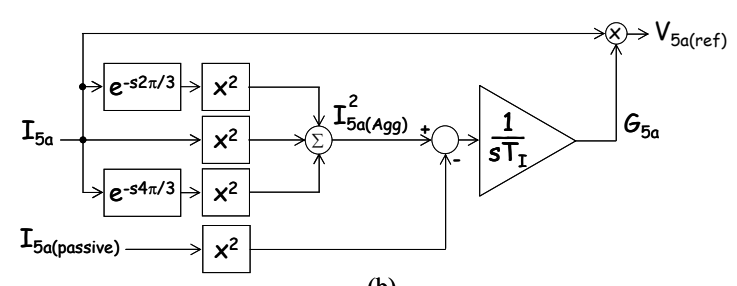

(b)

Fig. 7. Capacitor voltage control circuit (a) and $5^{\text {th }}$ harmonic current control circuit (b) for the series topology.

As presented in Figure 7.a, the control circuit in each phase compares a reference signal, $\mathrm{V}_{\mathrm{cc}(\mathrm{ref})}$, with the capacitor voltage, $\mathrm{V}_{\mathrm{cc}(\mathrm{a})}$, in phase $\mathrm{A}$ for example. The error passes through a low pass filter to eliminate the signal noise. Gain $\mathrm{G}_{\text {cap(a) }}$ is adjusted over the error filtered signal by a Proportional Integrator (PI) controller. The output of the PI controller is multiplied by an unit sinusoidal signal, $\mathrm{I}_{\mathrm{a}(\mathrm{PLL})}$, which is synchronized by the PLL as shown in Figure 6.a. Therefore, the output generates a fundamental voltage reference, $\mathrm{V}_{\mathrm{a}(\mathrm{ref})}$, responsible to control the capacitor voltage.

Figure 7.b shows the single-phase control circuit for the $5^{\text {th }}$ harmonic current in the passive filters. Instantaneous aggregate values concepts are applied to the $5^{\text {th }}$ harmonic detected current, $\mathrm{I}_{5 \mathrm{a}}$, extracted from the detection circuit, as shown in Figure 6.c, to obtain $\mathrm{I}_{5 \mathrm{a}}{ }^{2}(\mathrm{Agg})$, which is the sum of the square of the $5^{\text {th }}$ harmonic current and the square of that same current delayed by $120^{\circ}$ and $240^{\circ}$, as shown in (2).

$$
I_{5 a(\text { Agg })}^{2}=\left(I_{5 a}\right)^{2}+\left(I_{5 a} \cdot e^{j \frac{-2 \pi}{3}}\right)^{2}+\left(I_{5 a} \cdot e^{j \frac{-4 \pi}{3}}\right)^{2}
$$

This signal is compared with a $5^{\text {th }}$ harmonic reference

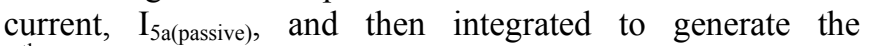
$5^{\text {th }}$ harmonic current control gain, $\mathrm{G}_{5 \mathrm{a}}$. This gain is multiplied by the $5^{\text {th }}$ harmonic current generating the $5^{\text {th }}$ harmonic voltage reference, $\mathrm{V}_{5 \mathrm{a}(\mathrm{ref})}$, responsible to control the $5^{\text {th }}$ harmonic current in the passive filters.

The reference signal, $\mathrm{I}_{5 \mathrm{a} \text { (ref) }}$, is a calculated value based on the maximum capacity of the $5^{\text {th }}$ harmonic current in the passive filters. The sum of the reference voltages, $\mathrm{V}_{\mathrm{a}(\mathrm{ref})}$ and $\mathrm{V}_{5 \mathrm{a} \text { (ref) }}$, results in a reference voltage that is used in an unipolar PWM inverter, generating the compensation voltage.

\section{SHUNT HYBRID FILTER}

\section{A. Power Circuit}

In the second proposed topology the hybrid filter is composed by a shunt connection involving an active filter and the existent passive filters. The power circuit consists of one single-phase voltage-source PWM inverter in each phase, with a switching frequency of $5 \mathrm{kHz}$ as well as the series configuration. The already presented high-pass passive filters, as shown in Figure 2, attenuate the high switching harmonics generated by the active filter. 
The connection in the system is made through a threephase transformer with turns ratio of 138:1 so that the power circuit could work with standard IGBT module without the necessity to connect more modules in series [7]. Figure 8 presents the hybrid filter shunt topology connected in the Ibiúna's $345 \mathrm{kV}$ bus.

The shunt hybrid filter, in spite of using a transformer, very high power semiconductors, $10 \mathrm{mF}$ capacitors and $10 \mu \mathrm{H}$ switching inductors in each phase, decreases the THD of the $345 \mathrm{kV}$ bus while protects the passive filters compensating the $5^{\text {th }}$ order overcurrent harmonic.

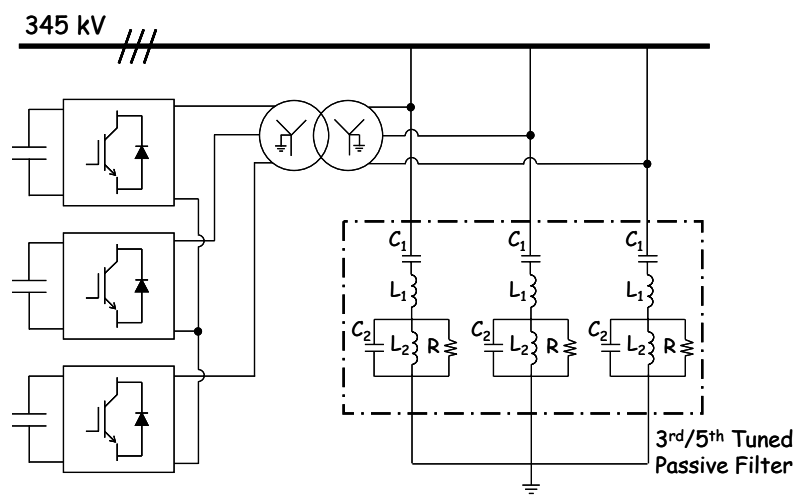

Fig. 8. Shunt hybrid filter connected to the $345 \mathrm{kV}$ bus.

\section{B. Operation Principles}

If the nominal current in the passive filters is not achieved the active filter remains in stand by mode, ready to operate. When an overcurrent is detected in the passive filters, the active filter generates a $5^{\text {th }}$ harmonic proportional current in order to eliminate the overcurrent only, in this case, making the passive filters work on the nominal capacity. The overcurrent operation is shown in Figure 9.

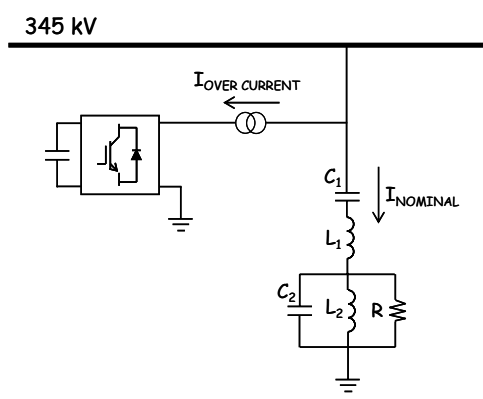

Fig. 9. Per phase shunt topology overcurrent operation.

\section{Detection Circuit}

The shunt topology uses a similar detection circuit to the one used by the series hybrid filter. The only difference is that the circuit uses a three-phase PLL to detect the fundamental voltage in the $345 \mathrm{kV}$ bus in order to control the capacitor voltages.

The output of the three-phase PLL used to detect the fundamental voltage is multiplied by five, as in Figure 6.b, and used to synchronize the $5^{\text {th }}$ harmonic current detector of Figure 6.c. The advantage of this topology is that the same PLL is used to detect the fundamental voltage and the $5^{\text {th }}$ harmonic current, as shown in Figure 10.

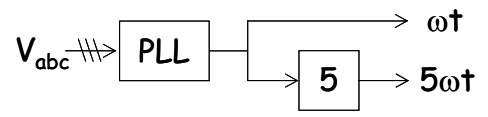

Fig. 10. PLL used in the detection circuit.

\section{Control Circuit}

The shunt hybrid filter control-circuit is also similar to the one used by the series hybrid filter. Here, one of the outputs of the detection circuit presented in Figure 10, $\omega \mathrm{t}$, is used to generate three unit sinusoidal signals which track the positive sequence bus voltage. In phase A for example, the signal is multiplied by the gain $\mathrm{G}_{\text {cap(a) }}$, , calculated the same way as in the series hybrid filter control circuit. As a result, the fundamental reference current, $\mathrm{I}_{\mathrm{a}(\mathrm{ref})}$, is generated.

To generate the $5^{\text {th }}$ harmonic reference current, $\mathrm{I}_{5 \mathrm{a}(\mathrm{ref})}$, the detected current, $I_{5 \mathrm{a}}$ ', is multiplied by a calculated gain, $\mathrm{G}_{5 \mathrm{a}}$ ', which is generated by a circuit similar to the one presented in Figure 7.b. The fundamental reference current, $\mathrm{I}_{\mathrm{a}(\mathrm{ref})}$, , and the $5^{\text {th }}$ harmonic reference current, $\mathrm{I}_{5 \mathrm{a} \text { (ref) }}$, are added and used in a fixed frequency feed forward PWM inverter to synthesize the compensation current.

\section{SIMULATION RESULTS}

\section{A. Series Hybrid Filter}

The simulation results with the series hybrid filter are presented from Figure 11 to Figure 19. The system was simulated during 45 seconds. During the first 15 seconds, not presented here, the system achieved the steady state where the passive filters nominal rms current $(55 \mathrm{~A} \mathrm{rms}$ in each of the two filters) was not achieved. In order to represent the variation of the harmonic pollution in the $345 \mathrm{kV}$ bus, two $5^{\text {th }}$ harmonic current sources are inserted in the system far from the $345 \mathrm{kV}$ bus. In 15.1 and 15.2 seconds the two harmonic pollutant sources are turned on, injecting $20 \mathrm{~A} \mathrm{rms}$ each, not achieving the nominal current of the passive filters. To simulate the overcurrent situation an extra $180 \mathrm{~A} \mathrm{rms}$ current is injected by one of the pollutant sources in 31 seconds after the beginning of the simulation.

The switching control circuit starts to operate after 16 seconds of simulation. In 16.05 seconds the active filter is connected in the system through a breaker. The capacitor voltage and the $5^{\text {th }}$ harmonic control circuits start up in 16.1 and 16.2 seconds respectively.

Figure 11 shows the response of the $5^{\text {th }}$ harmonic detection circuit. Figure 11.a presents the $5^{\text {th }}$ harmonic negative sequence in the passive filters, $\mathrm{FFT}_{(\mathrm{neg})}$, calculated using a Fast Fourier Transform (FFT) based on a sample data window, and also the negative sequence, $\operatorname{Detect}_{(\text {neg) }}$, extracted by the detection circuit. In the same way, Figure 11.b presents the calculated and extracted $5^{\text {th }}$ harmonic positive sequence, $\mathrm{FFT}_{(\text {pos })}$ and Detect $($ pos) respectively. It can be observed that besides the $5^{\text {th }}$ harmonic negative sequence injected in the system, a small $5^{\text {th }}$ harmonic positive sequence is generated by the asymmetries in the transmission lines (non-ideally transposed) and the HVDC firing control. This results show that the detection circuit detects all the $5^{\text {th }}$ harmonic current in the passive filters. 


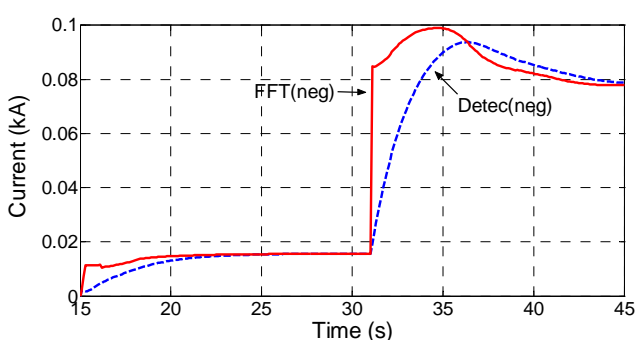

Fig. 11.a FFT(neg) and Detect(neg) in the passive filters.

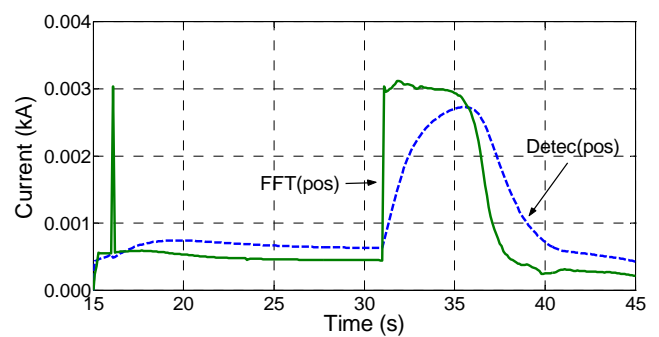

Fig. 11.b FFT(pos) and Detect(pos) in the passive filters.

The regulated capacitor voltages for all three phases are presented in Figure 12. After 16.1 seconds, the capacitor voltages are charged following the reference value. When the overcurrent is injected in the system, after 31 seconds, a variation in the capacitor voltages can be noted. However, the maximum variation in the capacitor voltages is less then $10 \%$ of the reference voltage, providing an adequate power so that the $5^{\text {th }}$ harmonic can be generated. Capacitances of $1 \mathrm{mF}$ are used in the simulations.

Figure 13 shows the gains $G_{\text {cap(a) }}, G_{c a p(b)}$ and $G_{\text {cap(c) }}$, used to regulate the capacitor voltage in each phase. In 16.1 seconds, when the capacitor voltage control circuits start up, a high gain is generated in order to charge the capacitors (not presented here because of the sampling resolution).

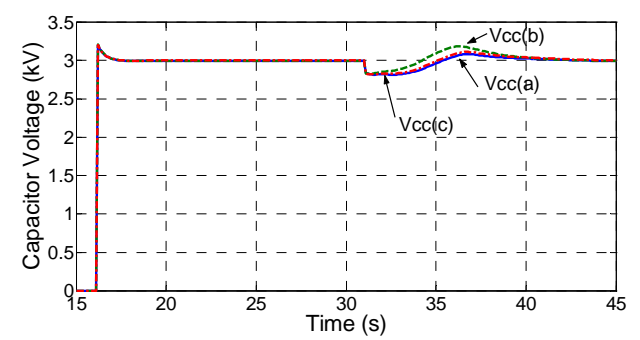

Fig. 12 Capacitor voltages.

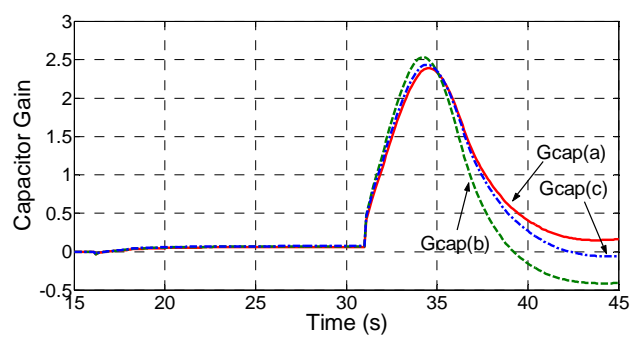

Fig. 13 Capacitor gains.

The gains $\mathrm{G}_{5 \mathrm{a}}, \mathrm{G}_{5 \mathrm{~b}}$ and $\mathrm{G}_{5 \mathrm{c}}$, presented in Figure 14 , can be interpreted as resistances, as illustrated in Figure 5. When the passive filters current is under its nominal current, from 15 to 31 seconds, the gains has a negative value, making the active filter behaves like a negative resistance. The lower limit of the integrator is adjusted to have the same value of the passive filters resistance at the $5^{\text {th }}$ harmonic frequency, which can be obtained in (1). This limit is used to prevent that the absolute value of the resistance generated by the active filter becomes higher than the resistance of the passive filters, avoiding the insertion of extra harmonic voltages at the bus.

From 31 to 45 seconds, the gains reach a positive value, making the active filter behave like a positive resistance. Figure 15 shows the phases of the $5^{\text {th }}$ harmonic current in the passive filters and the $5^{\text {th }}$ harmonic voltage generated by the active filter. As explained, from 15 to 31 seconds, the voltage and current $5^{\text {th }}$ harmonics are controlled to stay in counterphase. From 31 to 45 seconds, this harmonics have to reach the same phase.

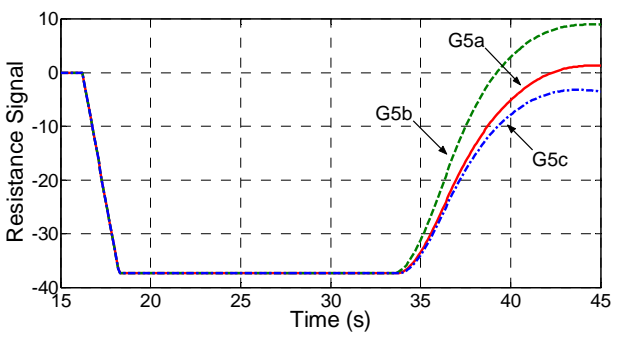

Fig. 14 Resistance gains.

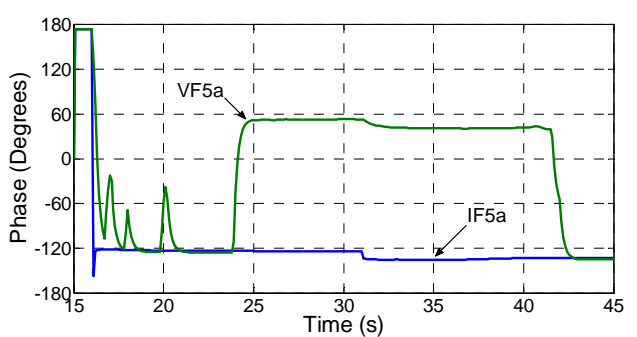

Fig. 15 Phases of $5^{\text {th }}$ harmonic current and $5^{\text {th }}$ harmonic voltage.

Figure 16 shows the harmonic spectrum of the phase voltages in the $345 \mathrm{kV}$ bus. When the active filter improves the quality factor of the passive filters, the $5^{\text {th }}$ harmonic voltage at the bus decreases (from $0.16 \%$ to $0.075 \%$ ). When the active filter protects the passive filters from an overcurrent, the $5^{\text {th }}$ harmonic voltage increases as expected, achieving $1.3 \%$. This value is in accordance with ONS standards $\left(2 \%\right.$ for the $5^{\text {th }}$ harmonic). During an overcurrent situation, without the active filter, the passive filters would have to be disconnected resulting in a value beyond the $2 \%$ standard. In both cases a negligible harmonic content in the switching frequency is observed.

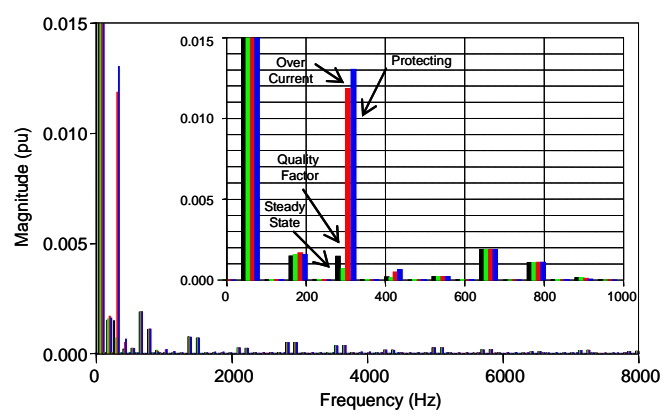

Fig. 16 Harmonic spectrum of the voltages in the $345 \mathrm{kV}$ bus. 
Figure 17 presents the modules of the $5^{\text {th }}$ harmonic currents for phase A in the lines directly connected at the $345 \mathrm{kV}$ bus of the circuit shown in Figure 2. The simulated harmonic pollution enters in the $345 \mathrm{kV}$ bus via the transmission line coming from Interlagos (curve A). At 31 seconds, this $5^{\text {th }}$ harmonic current raises instantly. Curve B represents the total current of all filter banks, including the $5^{\text {th }}$ harmonic filters. It can be observed that this total current is higher in the overcurrent situation. The other lines coming from the two bipoles, Guarulhos, synchronous compensators, Tijuco Preto and the $500 / 345 \mathrm{kV}$ transformers, respectively curves $\mathrm{C}$ until $\mathrm{G}$, are not significantly affected by the active filter. Other harmonics $\left(3^{\circ}, 4^{\circ}, 6^{\circ}, 7^{\circ}, 11^{\circ}\right.$ and $\left.13^{\circ}\right)$ were analyzed in the simulation as well. However, those harmonics did not present any significant variation when the series active filter entered in the system.

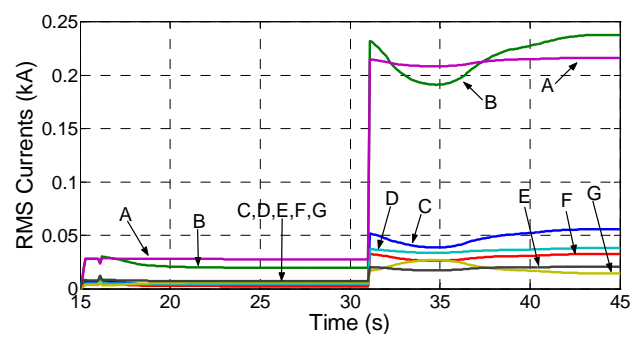

Fig. $175^{\text {th }}$ harmonic currents entering at the $345 \mathrm{kV}$ bus.

Figure 18 shows the $5^{\text {th }}$ harmonic rms current in the passive filters. From 15 to 31 seconds, when the filter nominal current is not achieved, the active filter cancels the resistance of the passive filters, increasing the $5^{\text {th }}$ harmonic rms current. From 31 to 45 seconds, when an overcurrent is detected, the active filter increases the resistance of the passive filters, protecting them against an overcurrent situation. A 10 seconds lag, caused by a delay in the detection circuit as shown in Figure 11, can be observed in the response of the series active filter. This lag does not compromise the operation of the passive filters, since the integration time of its protection is 20 minutes.

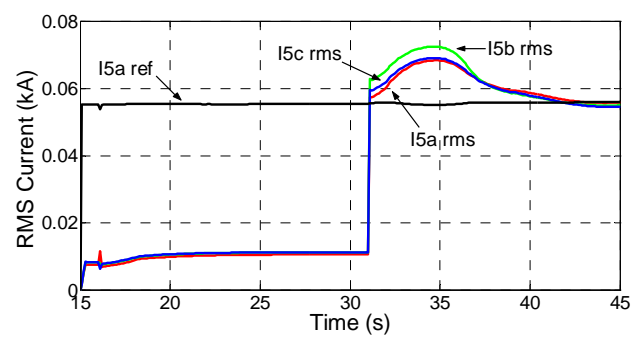

Fig. $185^{\text {th }}$ harmonic currents in the passive filters and its reference for phase $\mathrm{A}$.

In order to analyze the instantaneous performance of the series hybrid filter, Figure 19 presents a $50 \mathrm{~ms}$ interval with the voltage at the $345 \mathrm{kV}$ bus (in $\mathrm{kV}$ ), the output voltage generated by the active part of the series hybrid filter (in $\mathrm{kV}$ multiplied by 100) and the current at the hybrid filter (in kA multiplied by 1000) for phase A. At this interval the active filter generates a fundamental voltage in counter-phase with the fundamental current and a $5^{\text {th }}$ harmonic voltage in phase with the $5^{\text {th }}$ harmonic current at the passive filters, in order to discharge the capacitors and protect the passive filters respectively.

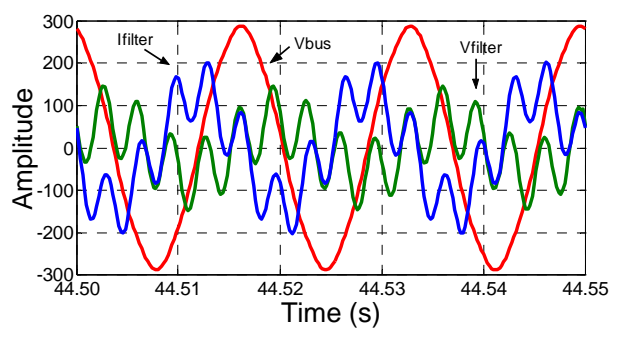

Fig. 19 Instantaneous performance of the series hybrid filter for phase A.

\section{B. Shunt Hybrid Filter}

The simulation results with the shunt hybrid filter are presented from Figure 20 to Figure 27. The system was simulated during 40 seconds. Similar to the series hybrid filter simulation, in the first 15 seconds the system achieved the steady state and in 15.1 and 15.2 seconds two pollutant sources, $20 \mathrm{~A}$ rms each, were injected far from the $345 \mathrm{kV}$ bus to represent the $5^{\text {th }}$ harmonic pollution in the system. As the overcurrent situation in the passive filters was not achieved, in 15.3 seconds one of the pollutant sources goes from 20 A to $200 \mathrm{~A} \mathrm{rms}$, injecting 123, 117 and $113 \mathrm{~A} \mathrm{rms} \mathrm{in}$ the two passive filters, in phases $\mathrm{A}, \mathrm{B}$ and $\mathrm{C}$, respectively, divided equally over the two identical passive filters.

In 16.0 seconds after the beginning of the simulation a breaker is switched to connect the active filter in the system. At this time the IGBTs are kept opened so that the capacitors in each phase are pre-charged through the diodes. The precharge occurs almost instantaneously but is not enough to charge the capacitors with the reference voltage $(3 \mathrm{kV})$. In 16.1 seconds the capacitor voltages and the $5^{\text {th }}$ harmonic control circuits start up and in 16.2 seconds the switching control circuit begins to operate, unblocking the IGBTs.

Figure 20 shows the response of the detection circuit for the negative sequence of the $5^{\text {th }}$ harmonic current in the passive filters. The detected $5^{\text {th }}$ harmonic negative sequence current, Detect ${ }_{(\text {neg) }}$,', is compared with the $5^{\text {th }}$ harmonic negative sequence current, FFT $_{(\text {neg) }}$, , calculated the same way as in the series hybrid filter case. Despite a short delay, it can be observed that both curves achieve the same value, confirming the efficiency of the detection circuit.

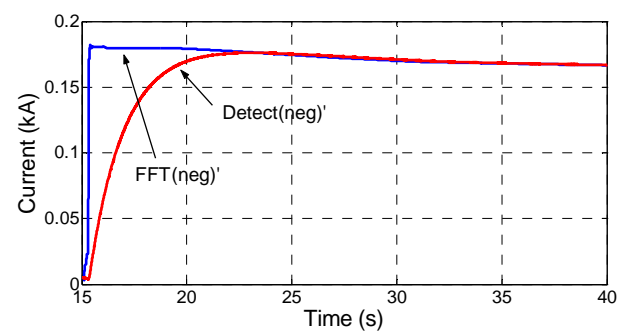

Fig. 20 FFT(neg)' and Detect(neg)' in the passive filters.

The capacitor voltages and the gains, generated to regulate these voltages, are presented in Figures 21 and 22, respectively. Variations in the voltages occur when the pollutant overcurrent enters in the system. Figure 22 presents 
the gains, adjusted by the control circuit, to provide a variation less than $10 \%$ of the reference voltage.

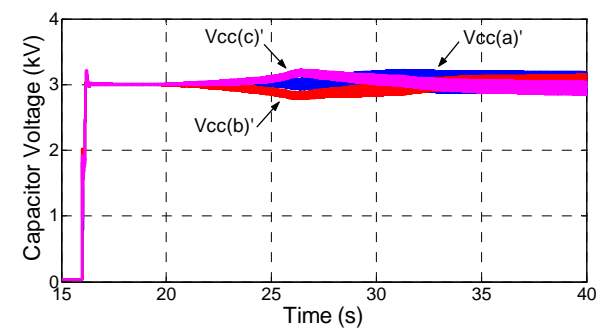

Fig. 21 Capacitor voltages.

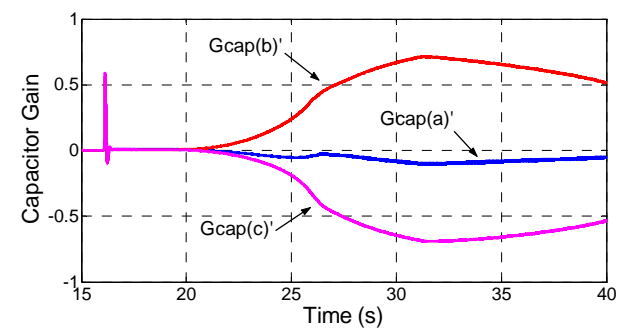

Fig. 22 Capacitor gains.

Figure 23 shows the gains that control the $5^{\text {th }}$ harmonic compensation current generated by the active filter. These gains, adjusted by the control circuit, start to rise when the current in the passive filters passes beyond its nominal value. After few seconds, these gains achieve a limit that is calculated for the active filters to operate in the linear region.

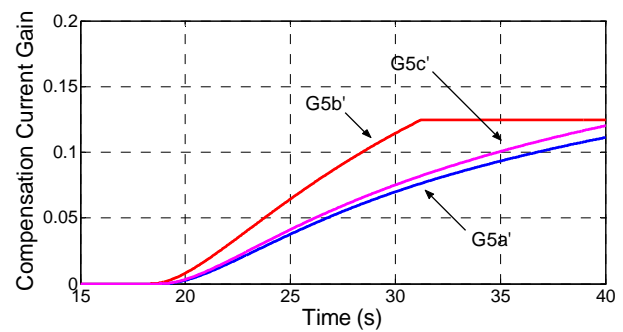

Fig. $235^{\text {th }}$ harmonic compensation current gains.

In Figure 24 the harmonic spectrum of the phase voltage in the $345 \mathrm{kV}$ bus can be observed before and after the actuation of the shunt active filter. As it can be observed, the $5^{\text {th }}$ harmonic distortion is reduced and there is a negligible harmonic content in the switching frequency. In Figure 25 the passive filters overcurrent protection is shown through the decrease of the 5th harmonic rms current when the control circuit starts to operate.

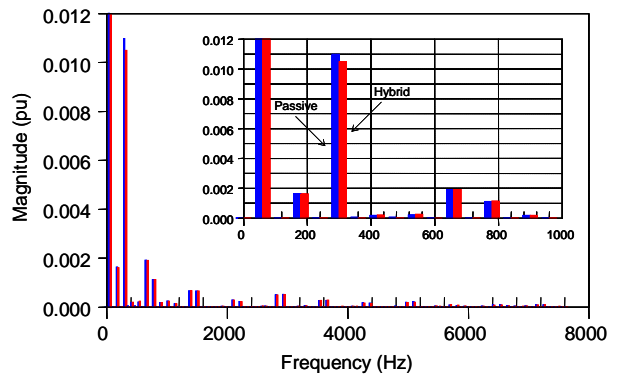

Fig. 24 Harmonic spectrum of the voltages in the $345 \mathrm{kV}$ bus.

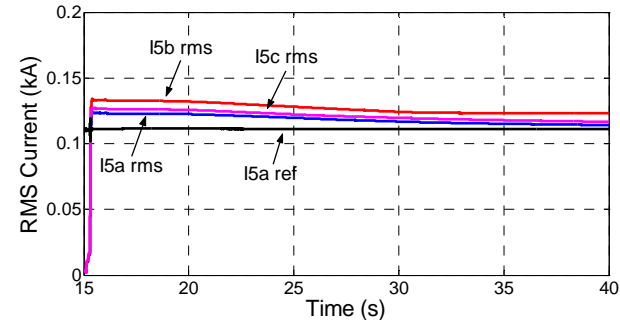

Fig. 25 The total $5^{\text {th }}$ harmonic currents in the two passive filters and its reference for phase A.

Figure 26 shows the same variables presented in Figure 17 for the series hybrid filter. For the shunt hybrid filter the extra 180 A rms does not enter in 31 seconds, but in 16 seconds. As it can be seen, curve $A$ is the same as in the case of the series hybrid filter, but in this case, curve B is descending near reaching the value of the entering pollution (curve A). In this case, as well as in the other lines, the harmonics are not significantly affected by the active filter.

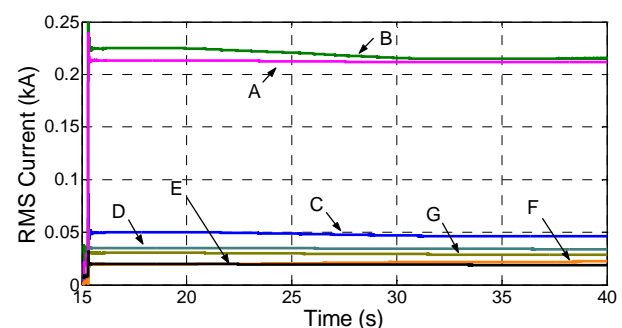

Fig. $265^{\text {th }}$ harmonic currents entering at the $345 \mathrm{kV}$ bus.

The instantaneous voltage at the $345 \mathrm{kV}$ bus (in $\mathrm{kV}$ ) and the currents in the active and passive parts for phase A of the shunt hybrid filter are presented in Figure 27. It can be observed that the current in the passive filters (in $\mathrm{kA}$ multiplied by 1000) is in phase with the current in the active filter (in kA multiplied by 2000).

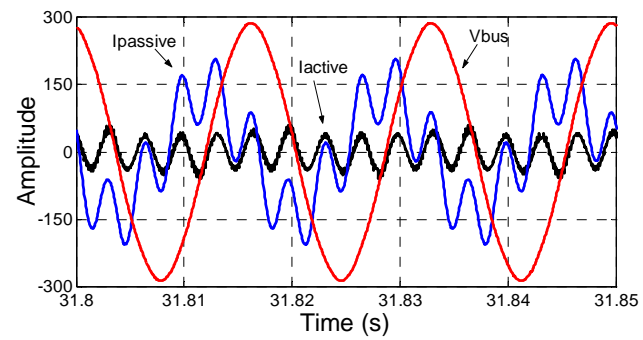

Fig. 27 Instantaneous performance of the shunt hybrid filter for phase A.

\section{CONCLUSION}

This work has presented a comparative study on two different topologies of hybrid filters with the objective to solve the problem of $5^{\text {th }}$ harmonic overcurrents in passive filters in an electric power transmission system, adapting the operation limits of the semiconductor devices with the high power levels of the transmission systems. The simulations with both topologies presented satisfactory results.

Besides limiting the passive filters current, the series hybrid filter also improves the quality factor of the filter 
when the nominal current is not achieved. Other important advantages of this topology are its small rated power circuit and the absence of matching transformers.

The results with the shunt hybrid filter showed its efficiency to compensate the overcurrent in the passive filters and its effectiveness to improve the THD of the $345 \mathrm{kV}$ bus where the active filter is installed. A matching transformer is necessary in this case.

Future works in this area would be the application of multilevel power circuits to increase the current capacity of the shunt hybrid filter and prototype implementations

\section{ACKNOWLEDGEMENT}

The authors would like to thank Furnas Centrais Elétricas S.A, CNPq and CAPES for financial support of this project.

\section{REFERENCES}

[1] E. H. Watanabe, M. Aredes, "Power Considerations on Shunt/Series Current and Voltage Conditioners", $10^{\text {th }}$ International Conference on Harmonic and Quality of Power, vol. 2, pp. 595-600, October 2002.

[2] P. Jintakosonwit, H. Fujita, H. Akagi, S. Ogasawara, "Implementation and Performance of Cooperative Control of Shunt Active Filters for Harmonic Damping Throughout a Power Distribution System", IEEE Transactions on Industry Applications, vol. 39, issue 2, pp. 556-564, March-April 2003.

[3] P. Enjeti, W. Shireen, I. Pitel, "Analysis and Design of an Active Power Filter to Cancel Harmonic Currents in Low Voltage Electric Power Distribution Systems", Proceedings of The International Conference on Power Electronics and Motion Control, vol. 1, pp. 368-373, November 1992.

[4] A. Plaisant, J. Reeve, "An Active Filter for AC Harmonics from HVDC Converters - Basic Concepts and Design Principles", IEEE Power Engineering Society Summer Meeting, vol. 1, pp. 395-400, July 1999.

[5] H. Fujita, T. Yamasaki, H. Akagi, "A Hybrid Active Filter for Damping of Harmonic Resonance in Industrial Power Systems", IEEE Transactions on Power Electronics, vol. 15, no. 2, pp. 215-222, March 2002.

[6] Xiao Xiangning,, Xu Yonghai, Liu Hao, Ma Yulong, "Experimental Study and Comparison of Hybrid Active Filter with Parallel Active Filter", The Fifth International Conference on Power Electronics and Drive Systems, vol. 1, pp. 566-571, November 2003.

[7] K. Satoh, M. Yamamoto, "The Present State of the Art in High-Power Semiconductor Devices", Proceedings of the IEEE, vol. 89, no. 03, pp. 813-821, June 2001.

[8] E. M. Sasso, G. G. Sotelo, A. A. Ferreira, E. H. Watanabe, M. Aredes, P. G. Barbosa, "Investigação dos Modelos de Circuitos de Sincronismo Trifásicos Baseados na Teoria das Potências Real e Imaginária Instantâneas (p-PLL e q-PLL)", XIV Congresso Brasileiro de Automática, pp. 480-485, September 2002.

[9] D. R. Costa Jr., L. G. B. Rolim, M. Aredes, “Analysis and Software Implementation of a Robust Synchronizing Circuit - PLL Circuit", IEEE International Symposium on Industrial Electronics, vol. 1, pp. 292-297, June 2003.

\section{BIOGRAPHIES}

Lucas Frizera Encarnação was born in Vitória, Espírito Santo State, Brazil, on December 27, 1979, and received the B.Sc. degree in electrical engineering from The Federal University of Espírito Santo in 2003.

In 2004 he joined the Power Electronic Laboratory group at COPPE/Federal University of Rio de Janeiro as a M.Sc. student. His research area includes active filters, static compensators and power quality.

Alexandre Guimarães Mercon was born in Vitória, Espírito Santo State, Brazil, on November 14, 1978, and received the B.Sc. degree in electrical engineering from The Federal University of Espírito Santo in 2003.

Since 2004, he is engaged in research projects in the Power Electronics Laboratory at COPPE/Federal University of Rio de Janeiro, where he is currently working towards the M.Sc. degree in power electronics. His research interests include active filters, power converters, FACTS devices and power quality.

Hélio Hayashi de Almeida was born in Curitiba, Paraná State, Brazil, on October 14, 1970, and received the B.Sc. degree in Electronic Engineering from the Federal University of Rio de Janeiro in 1993.

Since 1994 he worked in Furnas Centrais Elétricas S.A. in the Special Studies Division. His work includes real time simulations tests and FACTS devices (HVDC, SVC, TCSC).

Emanuel L. van Emmerik was born in The Hague, ZuidHolland, The Netherlands, on October 25, 1968, and received the M.Sc. degree (hons.) in electrical engineering from The Technical University of Delft in 1991, where continued as a Ph.D. student.

From 1999 to 2001 he worked for Ned Train Consulting as an $R \& D$ consultant. In 2002 he became a R\&D engineer in the Power Electronics Laboratory at COPPE/Federal University of Rio de Janeiro, where he is working nowadays. His main research area includes FACTS systems, electrical energy distribution and transmission, electrical motors and its control.

Maurício Aredes was born in the São Paulo State, Brazil, on August 14, 1961, receiving the B.Sc. degree from the Fluminense Federal University in 1984, the M.Sc. degree from the Federal University of Rio de Janeiro in 1991, and the Dr.-Ing. degree (hons.) from Technische Universität Berlin, Germany, in 1996, all in electrical engineering.

From 1985 to 1997 he worked in some major projects and within CEPEL (Centro de Pesquisas de Energia Elétrica), Rio de Janeiro, as R\&D Engineer. In 1997, he became an Associate Professor at the Federal University of Rio de Janeiro, where he teaches power electronics. His main research area includes HVDC and FACTS systems, active filters, custom power and power quality issues.

Dr. Aredes is a member of the Brazilian Power Electronics Society, the Brazilian Society for Automation Control, as well as IEEE. 